\title{
WITHDROWN: Osteonecrosis of the jaw in patients traited by denosumab for malignant bone disease: Descriptive study on 9 cases
}

\author{
Romain Lan ${ }^{1,4}$, Mehdi Hadj-Saïd ${ }^{1,2,5}$, Jean-Marc Foletti ${ }^{3,4}$, Eugénie Massereau ${ }^{1,2}$, Cyrille Chossegros ${ }^{2,4}$
}

\begin{abstract}
${ }^{1}$ DDS MSc, Oral Surgeon, Senior Resident in Oral Surgery, PhD Student, Aix-Marseille University. APHM. Timone Hospital, Pr Tardieu, Department of Oral Surgery and Odontology, Marseille, France. UMR 7268 ADES, Aix-Marseille University/EFS/ CNRS, Faculty of Medicine, 13344 Marseille, France

${ }^{2}$ DDS, MSc, Resident in Oral surgery, PhD Student, Aix-Marseille University. APHM, Timone Hospital, Pr Tardieu, Department of Oral Surgery and Odontology, Marseille, France. APHM, Conception Hospital, Pr Chossegros, Department of maxillofacial surgery, Marseille, France. UMR 6057 LPL, Aix-Marseille University/EFS/CNRS, Faculty of Medicine, 13344 Marseille, France ${ }^{3} \mathrm{MD}, \mathrm{PhD}$, Oral and Maxillofacial Surgeon, Aix-Marseille University. APHM, Nord Hospital, Pr Guyot, Department of maxillofacial surgery, Marseille, France. UMR 7268 ADES, Aix-Marseille University/EFS/CNRS, Faculty of Medicine, 13344 Marseille, France

${ }^{4}$ MD, MSc, Oral Surgeon, Resident in Oral Surgery, Aix-Marseille University. APHM, Timone Hospital, Pr Tardieu, Department of Oral Surgery and Odontology, Marseille, France. APHM, Conception Hospital, Pr Chossegros, Department of maxillofacial surgery, Marseille, France

${ }^{5} \mathrm{MD}$, PhD, Professor, Oral and Maxillofacial Surgeon, Aix-Marseille UniveDsity. APHM, Conception Hospital, Pr Chossegros, Department of maxillofacial surgery, Marseille, France. UMR 7268 ADES, Aix-Marseille University/EFS/CNRS, Faculty of Medicine, 13344 Marseille, France
\end{abstract}

Correspondence:

Timone Hospital, Pr Tardieu

Department of Oral Surgery and Odontology

264 rue St Pierre

13385, Marseille, France

lanromain@live.fr

Received: $12 / 08 / 2017$ Accepted: $23 / 12 / 2017$
Please cite this article in press as: Lan R, Hadj-Said M, Foletti JM, Massereau E, Chossegros C. Withdrown:Osteonecrosis of the jaw in patients traited by denosumab for malignant bone disease: descriptive study on 9 cases. Med Oral Patol Oral Cir Bucal. (2018), doi:10.4317/medoral.22312

\section{Abstract: Ahead of Print article withdrawn by publisher}

